\title{
Mathematical Modeling for Flood Mitigation: Effect of Bifurcation Angles in River Flowrates
}

\author{
Iskandar Shah Mohd Zawawi ${ }^{1, *}$, Nur Lina Abdullah², Hazleen Aris ${ }^{1}$, Badrul Amin Jaafar², \\ Nur Arif Husaini Norwaza ${ }^{2}$, Muhammad Haris Fadzillah Mohd Yunos ${ }^{2}$ \\ ${ }^{1}$ Institute of Informatics and Computing in Energy, Universiti Tenaga Nasional, Malaysia \\ ${ }^{2}$ Faculty of Computer and Mathematical Sciences, Universiti Teknologi MARA Negeri Sembilan, Malay sia
}

Received August 4, 2019; Revised October 12, 2019; Accepted December 15, 2019

Copyright $(2019$ by authors, all rights reserved. Authors agree that this article remains permanently open access under the terms of the Creative Commons Attribution License 4.0 International License

\begin{abstract}
This paper investigates the river flowrate at two branches of bifurcated river. The mathematical model from the literature is formulated based on momentum principle and mass continuity to cope with river flowrate at different bifurcation angles. The hydraulic variables, geometric properties of trapezoidal cross-sectional river and other physical characteristics of bifurcated river are provided, which may be assumed to be given beforehand for practical applications. An examp le of river bifurcation problem is given by UTM Centre for Industrial and Applied Mathematics (UTM-CIAM), Universiti Teknologi Malaysia. Maple software is used to implement the proposed model equation and generate the results. The amount of bifurcated river flowrate with different bifurcation angles is determined, resulting in a reasonable discussion. It is shown that for specific bifurcation angles, the river flowrates after the $b$ ifurcated junction are less than the critical flowrate. Finally, the results of applied problem indicate that the right-angled river bifurcation would be preferable to mitigate flood.
\end{abstract}

Keywords Bifurcation, Flowrate, Momentum Principle

\section{Introduction}

River bifurcation is the process that determines the distribution of flow, sediments and contaminants along the downstream river branches. This process is important in order to mitigate flood due to climate change. There have been several approaches in investigating the river bifurcation or bifurcated open-channel flow. For instance, [1] used both analytical and experimental ways to study the bifurcated open-channel flow. The channels used are of rectangular cross-sectional and the branch channel being set at a right-angled midway along the straight main channel. The estimation of the flowrate ratio in terms of the Froude number and the depth ratio had been obtained using theoretical model in [2]. The authors provided the experimental data for the validity of their proposed model.

Based on experimental observations, the work of [3] carried out a study on depth discharge relationship and energy-loss coefficient for a subcritical, equal-width, right-angled dividing subcritical flow over a horizontal bed in a narrow aspect ratio channel. The theoretical model for subcritical flows in dividing open channel junction is derived in [4] with the aid of the overall mass conservation together with the momentum principle in the streamwise direction to two control volumes through the junction. Further, a physical model with meandering features is constructed in [5] to investigate the effect of off-take angles on the flow distribution at a concave channel bifurcation.

A theoretical model for predicting depth of water with certain dividing angles has been proposed by [6]. The authors developed the model equations for both combining and dividing types of subcritical flows at channel junctions using the principal of momentu mbalance. The width of all the channels both in case of combining and dividing has been kept differently.

An unsteady mathematical model for predicting flow divisions at a right-angled open-channel junction [7] and hydrodynamic model $[8,9]$ for bifurcat ing stream was also done. More recently, the findings of nearly 10 years of researches into modeling bifurcation system with numerous simulation techniques have been reviewed [10].

However, none of the above work analy zes the effect of different bifurcation angles in river flowrate. In fact, the majority of the existing models are designed for a right-angled junction. Therefore, the aim of this paper is to investigate the behavior of river flowrates influenced by different bifurcation angles using mathematical model 
approach. The following section will describe the characteristics of the bifurcated channel and its geometric properties. Section 3 deals with the formulation of the mathematical model. An example of river bifurcation problem is given in Section 4. In section 5, the results are analyzed and discussed. Finally, some conclusions are made as well as the recommendation for future study.

\section{Methodology}

This section provides the detailed description of the channel and formulation of the model for the present study.

\subsection{Description of the Channel}

The characteristics of the bifurcated open-channel and its cross-sectional properties have to be considered for the equation of mathematical model. The schematic layout of the bifurcated channel is illustrated in Figure 1. A main channel is connected with two branch channels. The angles, $\theta_{1}$ and $\theta_{2}$ at the bifurcated junction are called bifurcation angles. For the application of momentum conservation law, we consider the boundaries of control volume as shown by the dotted line. The section has been positioned at the distance of two times the width of the channel at upstream and three times the width of the channel at downstream of the bifurcation.

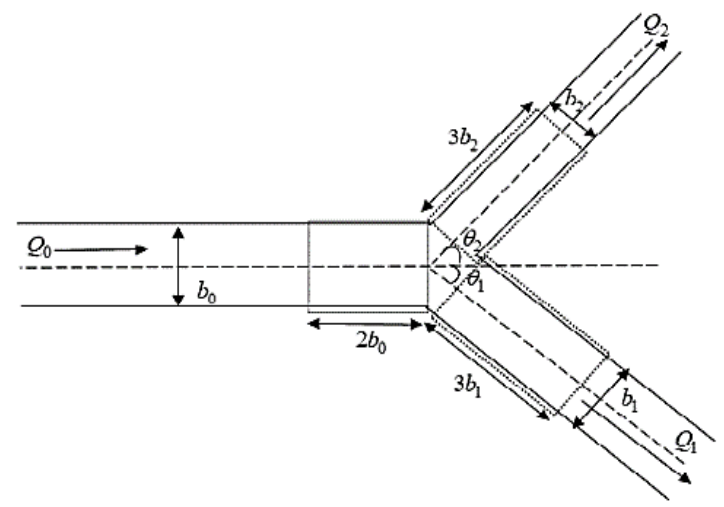

Figure 1. Schematic layout of the bifurcated channel: $Q=$ flowrate, $b=$ bottom width of channel, $\theta=$ bifurcation angles, $0=$ main channel, 1 = channel $1,2=$ channel 2

The channels are assumed to be uniform cross section. Channel cross sections can be considered to be either regular or irregular. A regular section is one whose shape does not vary along the length of the channel, whereas an irregular section will have changes in its geometry. The most common irregular section of open channel is a trapezoidal shape. The typical trapezoidal cross-sectional is shown in Figure 2.

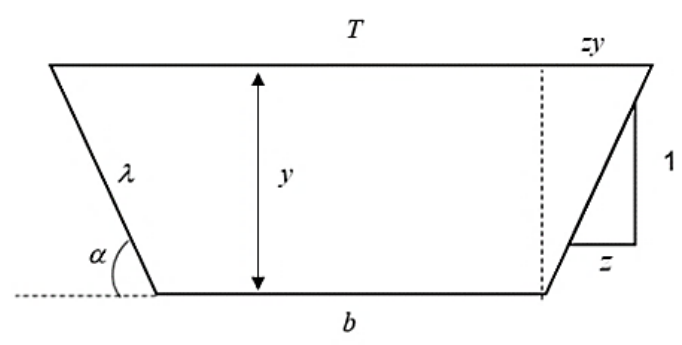

Figure 2. Geometric details of the typical trapezoidal cross-sectional: $\alpha=$ angle of the slope side, $b=$ bottom width, $y=$ depth of flow, $\lambda=$ wetted length measured along the slope side, $T=$ top width, $z=$ channel side slope

According to [11], flow hydraulics and momentum exchange in straight channels are significantly influenced by geometric and hydraulic variables. The cross-sectional area, $A$ is given by $A=b y+z y^{2}$, in which $b$ is the width of the channel bottom and $y$ is the depth of flow. The side slope is usually specified as horizontal : vertical, $z: 1$. Additional parameters for open channel flow are the wetted perimeter, $P_{w}$, the hydraulic radius, $R_{H}$ and the hydraulic depth, $D$. The wetted perimeter, $P_{W}=b+2 \lambda$ is the length of the line of contact between the water and the channel where the wetted length measured along the slope side is given by $\lambda=\sqrt{y^{2}+(y z)^{2}}$.

The hydraulic radius, $R_{H}$ is the area divided by the wetted perimeter, that is, $R_{H}=\frac{A}{P_{W}}$. The hydraulic depth is the area divided by the top width, $D=\frac{A}{T}$ where $T=b+2 z y$. Flow area is the cross-sectional area of the flow taken perpendicular to the flow direction.

Even though the river cross-sectional areas of the main channel and channel 1 are assumed to be similar, the capability of the channel to convey water can vary due to bifurcation angle. If the flowrate is unknown, a uniform velocity, $V$ that applies to an entire cross-sectional can be determined using Manning's equation [12, 13] as shown below:

$$
V=\frac{1}{n} R_{H}{ }^{0.66} S^{0.5}
$$

where $n$ is the roughness coefficient and $S$ is the average slope of channel. The dimensionless ratio of the inertial forces to gravitational forces acting on the flow is represented by Froude number, $F$ is defined as

$$
F=\frac{V}{\sqrt{g D}}=\frac{Q}{A \sqrt{g\left(\frac{A}{T}\right)}},
$$


where $V$ is the velocity, $D$ is the hydraulic depth and the gravitational acceleration, $g$ is $9.80665 \mathrm{~m} / \mathrm{s}^{2}$. The Froude number plays a significant role in open channel flow analysis. The hydraulic behavior of channel flow varies significantly depending on whether the flow is critical ( $F=1)$, subcritical $(F<1)$ or supercritical $(F>1)$.

The division of flowrate at bifurcated channel can be determined using the aid of mo mentumprinciple and mass continuity with the following assumptions:

(a) Main channel is straight prismatic channel, to which two branches of bifurcated junction are connected. All channels are trapezoidal cross-sectional.

(b) The flow is from main channel into channels 1 and 2 .

(c) The velocities and water surface elevations are constant across the channels at the inflow and outflow sections of the control volumes.

(d) The pressure distribution is hydrostatic at all sections of control volume.

(e) The geometrical properties such as channels width, channels depth, control volume lengths and slope of channel are known.

(f) The depth of flow in the main channel, channels 1 and 2 are equal.

(g) The shear stresses on the flow surface due to wind, the effects of vertical acceleration and the wall friction force as compared to other forces are neglected.

\subsection{Formulation of the Model}

This section describes the detail formulation of mathematical model based on momentum principle and mass continuity [7]. The basic continuity equation is taken as starting point for the formulation,

$$
Q_{0}=Q_{1}+Q_{2} \text {, }
$$

where $Q_{0}=A_{0} V_{0}, Q_{1}=A_{1} V_{1}$ and $Q_{2}=A_{2} V_{2}$. The terms $Q_{0}, Q_{1}$ and $Q_{2}$ are flowrates, $A_{0}, A_{1}$ and $A_{2}$ are trapezoidal cross-sectional areas while $V_{0}, V_{1}$ and $V_{2}$ are velocities in main channel, channel 1 and channel 2 respectively. The hydrostatic force on the horizontal strip of $A$ will be $P=\gamma A$ where $A=b y+z y^{2}$ and $\gamma$ are the specific weight of water. Therefore, the total horizontal force can be determined as follows:

$$
P=\gamma \int_{0}^{y} b y+z y^{2} d A=\left[\frac{b y^{2}}{2}+\frac{z y^{3}}{3}\right]_{0}^{y}=\gamma\left(\frac{b y^{2}}{2}+\frac{z y^{3}}{3}\right) .(2)
$$

By apply ing the continuity equation (1) and mo mentum principle in the flow direction of the main channel, we obtain

$$
\begin{aligned}
& P_{0}-P_{2} \cos \theta_{2}-P_{1} \cos \theta_{1}-U_{2}-U_{1}-\Delta P= \\
& \frac{\gamma}{g}\left(Q_{2} V_{2} \cos \theta_{2}+Q_{1} V_{1} \cos \theta_{1}-Q_{0} V_{0}\right) .
\end{aligned}
$$

The terms of momentumtransfering from the main channel to the branch channels are given in the following forms [7]:

$$
U_{1}=\rho Q_{1} V_{0} C \sin \theta_{1}, U_{2}=\rho Q_{2} V_{0} C \sin \theta_{2},
$$

where

$$
C=\frac{5}{6}-\frac{F_{0}^{2}}{40}-\frac{k_{0}}{12 q_{r}}\left(\frac{1+2 k_{0}}{\left(1+k_{0}\right)^{2}}\right) .
$$

Noting that $\Delta P=\gamma\left(\frac{b_{0} y_{2}{ }^{2}}{2}+\frac{z y_{2}{ }^{3}}{3}\right)-P_{2} \cos \theta_{2}$ while the density of water, $\rho$ is related to $\gamma$ and $g$ which can be determined as $\rho=\frac{\gamma}{g}$. By moving the terms, $U_{1}$ and $U_{2}$ to the right hand side (RHS), (3) can be written as follows:

$$
\begin{aligned}
& P_{0}-P_{2} \cos \theta_{2}-P_{1} \cos \theta_{1}-\Delta P=\frac{\gamma}{g}\left[Q_{2} V_{2} \cos \theta_{2}\right. \\
& \left.+Q_{1} V_{1} \cos \theta_{1}-Q_{0} V_{0}+\rho Q_{2} V_{0} C \sin \theta_{2}+\rho Q_{1} V_{0} C \sin \theta_{1}\right] .
\end{aligned}
$$

By taking the left hand side (LHS) of (4), we have the following equation:

$$
P_{0}-P_{2} \cos \theta_{2}-P_{1} \cos \theta_{1}-\Delta P \text {. }
$$

Based on (2), we simplify (5) as follows:

$$
\begin{aligned}
& \gamma\left[\frac{1}{2}\left(b_{0} y_{0}^{2}-b_{0} y_{2}^{2}-b_{1} y_{1}^{2} \cos \theta_{1}\right)\right. \\
& \left.+\frac{z}{3}\left(y_{0}^{3}-y_{2}^{3}-y_{1}^{3} \cos \theta_{1}\right)\right] .
\end{aligned}
$$

Now taking the RHS of (4),

$$
\begin{aligned}
& \frac{\gamma}{g}\left[Q_{2} V_{2} \cos \theta_{2}+Q_{1} V_{1} \cos \theta_{1}-Q_{0} V_{0}\right. \\
& \left.+\rho Q_{2} V_{0} C \sin \theta_{2}+\rho Q_{1} V_{0} C \sin \theta_{1}\right] .
\end{aligned}
$$

Based on (1), we produce

$$
\begin{aligned}
& \frac{\gamma}{g}\left[\frac{Q_{2} Q_{2}}{A_{2}} \cos \theta_{2}+\frac{Q_{1} Q_{1}}{A_{1}} \cos \theta_{1}-\frac{Q_{0} Q_{0}}{A_{0}}\right. \\
& \left.+\frac{Q_{2} Q_{0}}{A_{0}} C \sin \theta_{2}+\frac{Q_{1} Q_{0}}{A_{0}} C \sin \theta_{1}\right] .
\end{aligned}
$$

By using algebraic manipulation in (8), yields 


$$
\begin{aligned}
& =\frac{\gamma Q_{0}^{2}}{g A_{0}}\left[\frac{1}{Q_{0}^{2}} \frac{Q_{2}^{2}}{A_{2} / A_{0}} \cos \theta_{2}+\frac{1}{Q_{0}^{2}} \frac{Q_{1}^{2}}{A_{1} / A_{0}} \cos \theta_{1}\right. \\
& \left.-1+C\left(\frac{Q_{2}}{Q_{0}} \sin \theta_{2}+\frac{Q_{1}}{Q_{0}} \sin \theta_{1}\right)\right] .
\end{aligned}
$$

Let the flowrate ratio, $q_{r}=\frac{Q_{1}}{Q_{0}}$. Based on (1) and $Q_{1}=Q_{0} q_{r}$, we get $Q_{0}=Q_{2}+Q_{0} q_{r}$ and subsequently produce $\frac{Q_{2}}{Q_{0}}=1-q_{r}$. Therefore, the following equation is obtained:

$$
\begin{aligned}
& \frac{\gamma Q_{0}^{2}}{g A_{0}}\left[\frac{\left(1-q_{r}\right)^{2}}{A_{2} / A_{0}} \cos \theta_{2}+\frac{q_{r}^{2}}{A_{1} / A_{0}} \cos \theta_{1} .\right. \\
& \left.-1+C\left(\left(1-q_{r}\right) \sin \theta_{2}+q_{r} \sin \theta_{1}\right)\right] .
\end{aligned}
$$

Knowing that

$$
\frac{Q_{0}^{2}}{g A_{0}}=\frac{Q_{0}^{2}}{g A_{0}} \times \frac{T_{0}}{T_{0}} \times \frac{A_{0}^{2}}{A_{0}^{2}}=\frac{Q_{0}^{2} T_{0}}{g A_{0}{ }^{3}} \frac{A_{0}^{2}}{T_{0}}=F_{0}^{2} \frac{A_{0}^{2}}{T_{0}} .
$$

Subsequently, yielding

$$
F_{0}^{2} \frac{b_{0}^{2} y_{0}^{2}+2 b_{0} z y_{0}^{3}+z^{2} y_{0}^{4}}{b_{0}+2 y_{0}} \text {. }
$$

Let $z=\frac{k_{0} b_{0}}{y_{0}}$ and factorize, we have

$$
F_{0}^{2} \frac{b_{0}^{2} y_{0}^{2}\left(1+2 k_{0}+k_{0}^{2}\right)}{b_{0}\left(1+2 k_{0}\right)}
$$

Hence, $\frac{Q_{0}^{2}}{g A_{0}}=F_{0}^{2} b_{0} y_{0}^{2} \frac{\left(1+k_{0}\right)^{2}}{\left(1+2 k_{0}\right)}$. The term $\frac{A_{2}}{A_{0}}$ can be written as follows:

$$
\frac{A_{2}}{A_{0}}=\frac{b_{2} y_{2}+z y_{2}^{2}}{b_{0} y_{0}+z y_{0}^{2}} .
$$

Let $\frac{y_{2}}{y_{0}}=y_{r}, \frac{b_{2}}{b_{0}}=B r_{2}$ and $\frac{b_{1}}{b_{0}}=B r_{1}$, we get

$$
\frac{A_{2}}{A_{0}}=\frac{b_{2} y_{2}+k_{0} b_{0} y_{2} y_{r}}{b_{0} y_{0}+k_{0} b_{0} y_{0}} \text {. }
$$

Similarly, the term $\frac{A_{1}}{A_{0}}$ is given by

$$
\frac{A_{1}}{A_{0}}=\frac{b_{1} y_{1}+\frac{k_{0} b_{0} y_{1}^{2}}{y_{0}}}{b_{0} y_{0}+\frac{k_{0} b_{0} y_{0}^{2}}{y_{0}}} .
$$

In our case, it has to be noted that the depths of all channels are equal, $y_{0}=y_{1}=y_{2}$. Thus, the depth ration is given by $y_{r}=\frac{y_{1}}{y_{0}}=\frac{y_{2}}{y_{0}}$. Equation (15) is written as follows:

$$
\frac{A_{1}}{A_{0}}=\frac{b_{1} y_{1}+k_{0} b_{0} y_{1} y_{r}}{b_{0} y_{0}+k_{0} b_{0} y_{0}} .
$$

By multiplying the numerator and denominator of (14) and (16) with $\frac{1}{b_{0} y_{0}}$, we obtain

$$
\begin{gathered}
\frac{A_{1}}{A_{0}}=\frac{\left(B r_{1}+k_{0} y_{r}\right) y_{r}}{1+k_{0}}, \\
\frac{A_{2}}{A_{0}}=\frac{\left(B r_{2}+k_{0} y_{r}\right) y_{r}}{1+k_{0}} .
\end{gathered}
$$

We substitute (17) and (18) into (10), yielding

$\gamma F_{0}^{2} b_{0} y_{0}^{2} \frac{\left(1+k_{0}\right)^{2}}{\left(1+2 k_{0}\right)}\left[\frac{\left(1-q_{r}\right)^{2}}{\left(B r_{2}+k_{0} y_{r}\right) y_{r} /\left(1+k_{0}\right)} \cos \theta_{2}\right.$

$+\frac{q_{r}^{2}}{\left(B r_{1}+k_{0} y_{r}\right) y_{r} /\left(1+k_{0}\right)} \cos \theta_{1}-1$

$\left.+C\left(\left(1-q_{r}\right) \sin \theta_{2}+q_{r} \sin \theta_{1}\right)\right]$.

Simplifying (19), we get

$\gamma F_{0}^{2} b_{0} y_{0}^{2} \frac{\left(1+k_{0}\right)^{2}}{\left(1+2 k_{0}\right)}\left[\frac{1+k_{0}}{y_{r}}\left(\frac{\left(1-q_{r}\right)^{2}}{\left(B r_{2}+k_{0} y_{r}\right)} \cos \theta_{2}\right.\right.$

$\left.\left.+\frac{q_{r}^{2}}{\left(B r_{1}+k_{0} y_{r}\right)} \cos \theta_{1}\right)-1+C\left(\left(1-q_{r}\right) \sin \theta_{2}+q_{r} \sin \theta_{1}\right)\right]$.

Finally, LHS of (6) is equal to RHS of (20) that becomes

$$
\begin{aligned}
& \frac{\left(1+2 k_{0}\right)}{b_{0} y_{0}{ }^{2}}\left[\frac{1}{2}\left(b_{0} y_{0}^{2}-b_{0} y_{2}^{2}-b_{1} y_{1}^{2} \cos \theta_{1}\right)\right. \\
& \left.+\frac{z}{3}\left(y_{0}^{3}-y_{2}^{3}-y_{1}^{3} \cos \theta_{1}\right)\right]=F_{0}^{2}\left(1+k_{0}\right)^{2} \\
& {\left[\frac{1+k_{0}}{y_{r}}\left(\frac{\left(1-q_{r}\right)^{2}}{\left(B r_{2}+k_{0} y_{r}\right)} \cos \theta_{2}+\frac{q_{r}^{2}}{\left(B r_{1}+k_{0} y_{r}\right)} \cos \theta_{1}\right)\right.} \\
& \left.-1+C\left(\left(1-q_{r}\right) \sin \theta_{2}+q_{r} \sin \theta_{1}\right)\right] .
\end{aligned}
$$


After simplification of (21), the general equation of bifurcated flow is obtained in the following form:

$$
\begin{aligned}
& \left(1+2 k_{0}\right)\left[\frac{1}{2}\left(1-y_{r}{ }^{2}-B r_{1} y_{r}^{2} \cos \theta_{1}\right)\right. \\
& \left.+\frac{k_{0}}{3}\left(1-y_{r}{ }^{3}-y_{r}{ }^{3} \cos \theta_{1}\right)\right]=F_{0}^{2}\left(1+k_{0}\right)^{2}\left[\frac{1+k_{0}}{y_{r}}\right. \\
& \left(\frac{\left(1-q_{r}\right)^{2}}{\left(B r_{2}+k_{0} y_{r}\right)} \cos \theta_{2}+\frac{q_{r}^{2}}{\left(B r_{1}+k_{0} y_{r}\right)} \cos \theta_{1}\right) \\
& \left.-1+C\left(\left(1-q_{r}\right) \sin \theta_{2}+q_{r} \sin \theta_{1}\right)\right] .
\end{aligned}
$$

\section{River Bifurcation Problem}

In this section, we give special attention to river bifurcation problem in Sungai Nenggiri, Gua Musang, Kelantan. Sungai Nenggiri that is geographically located in the north eastern part of Peninsular Malaysia within latitude $4.97024^{\circ}$ to $4.96951^{\circ}$ North and $101.77144^{\circ}$ to $101.77207^{\circ}$ East. This river is considered in this study due to serious floods' occurrence during Monsoon seas on in the past few years. Extensive flooding throughout the catchment occurs during heavy and prolonged rainfall resulting in high river flow. The river flow will overspill the banks of Sungai Nenggiri, disrupting road network and human life.

The main mitigation action that can be taken is by diverting some of Sungai Nenggiri's flow during peak flow to a new river, namely Sungai Anak Nenggiri. The amounts of river flow from Sungai Nenggiri (main channel) going through Sungai Nenggiri after the bifurcation junction (channel 1) and Sungai Anak Nenggiri (channel 2) are depending on the bifurcation angles, $\theta_{1}$ and $\theta_{2}$. The flowrate in the main channel is assumed to be $Q_{0}=1000 \mathrm{~m}^{3} / \mathrm{s}$ while $Q_{1}$ and $Q_{2}$ are the flowrates in channel 1 and channel 2 respectively. The critical flowrate in channel 1 is expected to be $Q_{1}=800 \mathrm{~m}^{3} / \mathrm{s}$. We theorize that if the flowrate exceeds this value, flood will occur in channel 1 . Therefore, (22) can be applied to determine the amount of flowrates in channel 1 and channel 2 with different bifurcation angles.

This general problem is given by UTM Centre for Industrial and Applied Mathematics (UTM-CIAM), Universiti Teknologi Malaysia. However, the real experimental data of Sungai Nenggiri is unavailable at this time for error analysis. For application purpose, we assume that the channels are normal, clean, straight, full stage, with no rifts or deep pools. Thus, $n=0.03$ is selected as manning's coefficient while the slope of the main channel is $S=0.0001814260235 \mathrm{~m}$. Since the Froude number for the main channel is $F_{0}=0.174902437$, it can be said that the flow is subcritical. The geometric and hydraulic properties of bifurcated channel used in the proposed model are presented in Table 1.

Table 1. Geometric and hydraulic properties (GHP) of bifurcated channe

\begin{tabular}{|c|c|c|c|}
\hline GHP & Main channel & Channel 1 & Channel 2 \\
\hline$\alpha$ & $60^{0}$ & $60^{0}$ & $60^{0}$ \\
\hline$y$ & $3.5 \mathrm{~m}$ & $3.5 \mathrm{~m}$ & $3.5 \mathrm{~m}$ \\
\hline$z$ & $4.081632657 \mathrm{~m}$ & $4.081632657 \mathrm{~m}$ & $0.859291084 \mathrm{~m}$ \\
\hline$T$ & $300 \mathrm{~m}$ & $300 \mathrm{~m}$ & $60.15037594 \mathrm{~m}$ \\
\hline$b$ & $271.285714 \mathrm{~m}$ & $271.285714 \mathrm{~m}$ & $54.13533835 \mathrm{~m}$ \\
\hline$A$ & $1000 \mathrm{~m}^{2}$ & $1000 \mathrm{~m}^{2}$ & $200 \mathrm{~m}^{2}$ \\
\hline$\lambda$ & $14.70821651 \mathrm{~m}$ & $14.70821651 \mathrm{~m}$ & $4.614668923 \mathrm{~m}$ \\
\hline$P_{W}$ & $300.8450044 \mathrm{~m}$ & $300.8450044 \mathrm{~m}$ & $63.3646762 \mathrm{~m}$ \\
\hline$R_{H}$ & $3.323970767 \mathrm{~m}$ & $3.323970767 \mathrm{~m}$ & $3.156332708 \mathrm{~m}$ \\
\hline$D$ & $3.33 \mathrm{~m}$ & $3.33 \mathrm{~m}$ & $3.325 \mathrm{~m}$ \\
\hline
\end{tabular}

\section{Results}

To analyze the results, the model (22) is performed using Maple software. The bifurcation angles, $\theta_{1}$ and $\theta_{2}$ considered in this study are $0^{0}, 15^{0}, 30^{0}, 45^{0}, 60^{0}, 75^{0}$ and $90^{0}$. The values of flowrate ratios, $q_{r}$, flowrates in channel $1, Q_{1}$ and flowrates in channel 2, $Q_{2}$ are tabulated in Tables 2-8. It has to be mentioned that $q_{r}$ is the ratio of flowrate in channel 1 to the flowrate in main channel. For simplicity, the graphical representations of flowrate ratios and bifurcation angles are shown in Figure 3.

Table 2. Flowrates in channels 1 and 2 when $\theta_{1}=0^{0}$

\begin{tabular}{|c|c|c|c|c|}
\hline$\theta_{1}$ & $\theta_{2}$ & $q_{r}$ & $Q_{1}, \mathrm{~m}^{3} / \mathrm{s}$ & $Q_{2}, \mathrm{~m}^{3} / \mathrm{s}$ \\
\hline 0 & 0 & 0.8067940552 & 806.7940552 & 193.2059448 \\
\hline 0 & 15 & 0.8227092780 & 822.7092780 & 177.2907220 \\
\hline 0 & 30 & 0.8284124759 & 828.4124759 & 171.5875241 \\
\hline 0 & 45 & 0.8214011067 & 821.4011067 & 178.5988933 \\
\hline 0 & 60 & 0.7928048911 & 792.8048911 & 207.1951089 \\
\hline 0 & 75 & 0.7125371460 & 712.5371460 & 287.4628540 \\
\hline 0 & 90 & 0.4161533812 & 416.1533812 & 583.8466188 \\
\hline
\end{tabular}

Table 3. Flowrates in channels 1 and 2 when $\theta_{1}=15^{0}$

\begin{tabular}{|c|c|c|c|c|}
\hline$\theta_{1}$ & $\theta_{2}$ & $q_{r}$ & $Q_{1}, \mathrm{~m}^{3} / \mathrm{s}$ & $Q_{2}, \mathrm{~m}^{3} / \mathrm{s}$ \\
\hline 15 & 0 & 0.7911862451 & 791.1862451 & 208.8137549 \\
\hline 15 & 15 & 0.8067650940 & 806.7650940 & 193.2349060 \\
\hline 15 & 30 & 0.8110586289 & 811.0586289 & 188.9413711 \\
\hline 15 & 45 & 0.8010471671 & 801.0471671 & 198.9528329 \\
\hline 15 & 60 & 0.7663678231 & 766.3678231 & 233.6321769 \\
\hline 15 & 75 & 0.6717559187 & 671.7559187 & 328.2440813 \\
\hline 15 & 90 & 0.3192905923 & 319.2905923 & 680.7094077 \\
\hline
\end{tabular}


Table 4. Flowrates in channels 1 and 2 when $\theta_{1}=30^{\circ}$

\begin{tabular}{|c|c|c|c|c|}
\hline$\theta_{1}$ & $\theta_{2}$ & $q_{r}$ & $Q_{1}, \mathrm{~m}^{3} / \mathrm{s}$ & $Q_{2}, \mathrm{~m}^{3} / \mathrm{s}$ \\
\hline 30 & 0 & 0.7869497049 & 786.9497049 & 213.0502951 \\
\hline 30 & 15 & 0.8027210236 & 802.7210236 & 197.2789764 \\
\hline 30 & 30 & 0.8067320739 & 806.7320739 & 193.2679261 \\
\hline 30 & 45 & 0.7957057968 & 795.7057968 & 204.2942032 \\
\hline 30 & 60 & 0.7582902466 & 758.2902466 & 241.7097534 \\
\hline 30 & 75 & 0.6546484797 & 654.6484797 & 345.3515203 \\
\hline 30 & 90 & 0.2401904453 & 240.1904453 & 759.8095547 \\
\hline
\end{tabular}

Table 5. Flowrates in channels 1 and 2 when $\theta_{1}=45^{0}$

\begin{tabular}{|c|c|c|c|c|}
\hline$\theta_{1}$ & $\theta_{2}$ & $q_{r}$ & $Q_{1}, \mathrm{~m}^{3} / \mathrm{s}$ & $Q_{2}, \mathrm{~m}^{3} / \mathrm{s}$ \\
\hline 45 & 0 & 0.7949051046 & 794.9051046 & 205.0948954 \\
\hline 45 & 15 & 0.8114393561 & 811.4393561 & 188.5606439 \\
\hline 45 & 30 & 0.8164352045 & 816.4352045 & 183.5647955 \\
\hline 45 & 45 & 0.8066871811 & 806.6871811 & 193.3128189 \\
\hline 45 & 60 & 0.7705429480 & 770.5429480 & 229.4570520 \\
\hline 45 & 75 & 0.6645994258 & 664.5994258 & 335.4005742 \\
\hline 45 & 90 & 0.1722446834 & 172.2446834 & 827.7553166 \\
\hline
\end{tabular}

Table 6. Flowrates in channels 1 and 2 when $\theta_{1}=60^{\circ}$

\begin{tabular}{|c|c|c|c|c|}
\hline$\theta_{1}$ & $\theta_{2}$ & $q_{r}$ & $Q_{1}, \mathrm{~m}^{3} / \mathrm{s}$ & $Q_{2}, \mathrm{~m}^{3} / \mathrm{s}$ \\
\hline 60 & 0 & 0.8159655445 & 815.9655445 & 184.0344555 \\
\hline 60 & 15 & 0.8339066727 & 833.9066727 & 166.0933273 \\
\hline 60 & 30 & 0.8414225983 & 841.4225983 & 158.5774017 \\
\hline 60 & 45 & 0.8358869677 & 835.8869677 & 164.1130323 \\
\hline 60 & 60 & 0.8066091461 & 806.6091461 & 193.3908539 \\
\hline 60 & 75 & 0.7097821934 & 709.7821934 & 290.2178066 \\
\hline 60 & 90 & 0.1112785518 & 111.2785518 & 888.7214482 \\
\hline
\end{tabular}

Table 7. Flowrates in channels 1 and 2 when $\theta_{1}=75^{0}$

\begin{tabular}{|c|c|c|c|c|}
\hline$\theta_{1}$ & $\theta_{2}$ & $q_{r}$ & $Q_{1}, \mathrm{~m}^{3} / \mathrm{s}$ & $Q_{2}, \mathrm{~m}^{3} / \mathrm{s}$ \\
\hline 75 & 0 & 0.8509646114 & 850.9646114 & 149.0353886 \\
\hline 75 & 15 & 0.8710508212 & 871.0508212 & 128.9491788 \\
\hline 75 & 30 & 0.8830122328 & 883.0122328 & 116.9877672 \\
\hline 75 & 45 & 0.8856383590 & 885.6383590 & 114.3616410 \\
\hline 75 & 60 & 0.8716827337 & 871.6827337 & 128.3172663 \\
\hline 75 & 75 & 0.8063916606 & 806.3916606 & 193.6083394 \\
\hline 75 & 90 & 0.0542840796 & 54.28407957 & 945.7159204 \\
\hline
\end{tabular}

Table 8. Flowrates in channels 1 and 2 when $\theta_{1}=90^{0}$

\begin{tabular}{|c|c|c|c|c|}
\hline$\theta_{1}$ & $\theta_{2}$ & $q_{r}$ & $Q_{1}, \mathrm{~m}^{3} / \mathrm{s}$ & $Q_{2}, \mathrm{~m}^{3} / \mathrm{s}$ \\
\hline 90 & 0 & 0.6742997042 & 674.2997042 & 325.7002958 \\
\hline 90 & 15 & 0.7031325671 & 703.1325671 & 296.8674329 \\
\hline 90 & 30 & 0.7164798741 & 716.4798741 & 283.5201259 \\
\hline 90 & 45 & 0.7131229768 & 713.1229768 & 286.8770232 \\
\hline 90 & 60 & 0.6837385036 & 683.7385036 & 316.2614964 \\
\hline 90 & 75 & 0.5844868749 & 584.4868749 & 415.5131251 \\
\hline 90 & 90 & 0.8198591028 & 819.8591028 & 180.1408972 \\
\hline
\end{tabular}

The amount of $Q_{1}$ is less than $800 \mathrm{~m}^{3} / \mathrm{s}$ when $\theta_{1}=0^{0}$ and $\theta_{2}=60^{0}, 75^{0}$ or $90^{0}$. If $\theta_{1}=30^{0}$, $Q_{1}$ is less than $800 \mathrm{~m}^{3} / \mathrm{s}$ except when $\theta_{2}=15^{0}$ or $30^{0}$. For $\theta_{1}=15^{0}$ or $45^{0}, Q_{1}$ is less than $800 \mathrm{~m}^{3} / \mathrm{s}$ when $\theta_{2}=0^{0}, 60^{0}, 75^{0}$ or $90^{0}$. It also can be observed that $Q_{1}$ is less than $800 \mathrm{~m}^{3} / \mathrm{s}$ when $\theta_{1}=60^{0}$ and $\theta_{2}=75^{0}$ or $90^{0}$. From Tables 2-7, it is observed that $Q_{1}$ decreases significantly when $\theta_{2}=90^{0}$. The lowest value of $Q_{1}$ is when $\theta_{1}=75^{0}$ and $\theta_{2}=90^{0}$ as presented in Table 7. However, $Q_{1}$ becomes greater than the critical flowrate when $\theta_{1}=\theta_{2}=90^{\circ}$. The values of bifurcation angle when $Q_{1}$ is less than the critical flowrate that is summarized in Table 9.

Table 9. Bifurcation angles when $q_{r}<0.8$

\begin{tabular}{|c|c|}
\hline$\theta_{1}$ & $\theta_{2}$ \\
\hline $0^{0}$ & $60^{0}, 75^{0}, 90^{0}$ \\
\hline $15^{0}$ & $0^{0}, 60^{0}, 75^{0}, 90^{0}$ \\
\hline $30^{\circ}$ & $0^{0}, 45^{0}, 60^{\circ}, 75^{0}, 90^{\circ}$ \\
\hline $45^{0}$ & $0^{0}, 60^{\circ}, 75^{0}, 90^{0}$ \\
\hline $60^{\circ}$ & $75^{\circ}, 90^{\circ}$ \\
\hline $75^{0}$ & $90^{\circ}$ \\
\hline $90^{0}$ & $0^{0}, 15^{0}, 30^{0}, 45^{0}, 60^{0}, 75^{0}$ \\
\hline
\end{tabular}
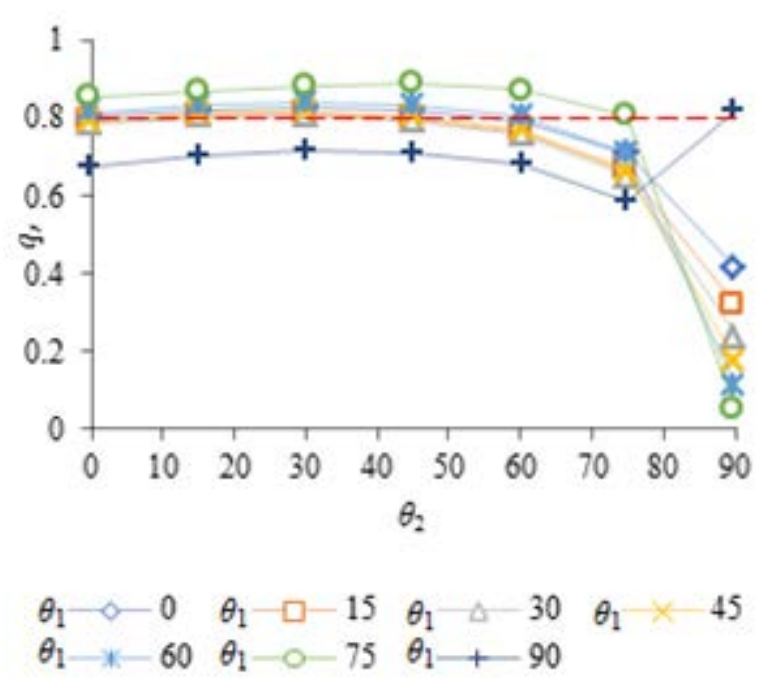

Figure 3. Graph of flowrate ratios, $q_{r}$ with respect to $\theta_{2}$ when $\theta_{1}=0^{0}, 15^{0}, 30^{0}, 45^{0}, 60^{0}, 75^{0}, 90^{0}$

Figure 3 shows the graph of $q_{r}$ versus $\theta_{2}$ where the values of $\theta_{1}$ are from $0^{0}$ to $90^{0}$. The horizontal 
dashed line at $q_{r}=0.8$ represents the critical flowrate ratio. For any $\theta_{1}$, it can be seen that $q_{r}$ approaches to the critical flowrate ratio except when $\theta_{2}=90^{\circ}$. To avoid over-flow in channel 1 , both $\theta_{1}$ and $\theta_{2}$ cannot be $90^{0}$.

From the results obtained, it can be observed that the right-angled bifurcation at one of the branches (either $\theta_{1}=90^{0}$ or $\theta_{2}=90^{0}$ ) would be efficient to reduce the amount of flowrates in channel 1 significantly. However, T-junction (when both $\theta_{1}$ and $\theta_{2}$ are $90^{\circ}$ ) is not recommended.

\section{Conclusions}

This study provides insightful information for understanding of the open-channel flow and assists engineering design of river bifurcation. The mathematical model is derived based on continuity equation, mo mentum principle and some algebraic manipulations to predict the bifurcated river flowrates with different bifurcation angles. The model equation consists of Froude number and various important parameters such as bifurcation angles, width of channels, depth of flows and flowrates in branches of river. Thus, it can be applied for other rivers with different geometric properties. The analysis of the results reveals that the river flowrate after the bifurcated junction is below the critical flowrate if an appropriate bifurcation angles are considered. The implementation of right-angled bifurcation at Sungai Nenggiri can be an alternative action to mitigate flood.

In future study, the mathematical model for river bifurcation with different bifurcation angles can be investigated when the problem concerning the recirculation region is understood. Other interesting features that can be observed are the hydraulic jumps and the surface discontinuity. Furthermore, other minor factors affect the river bifurcation flowrate such as wall frictions and external forces that should be considered.

\section{Nomenclatures}

$\begin{array}{ll}A: & \text { Cross-sectional area of the channel } \\ C: & \text { Constant } \\ F: & \text { Froude number } \\ g: & \text { Gravitational acceleration } \\ k: & \text { Side slope x flow depth to bottom width ratio } \\ P: & \text { Pressure force } \\ P_{W}: & \text { Wetted perimeter } \\ Q: & \text { Flowrate } \\ q_{r}: & \text { Flowrate ratio }\end{array}$

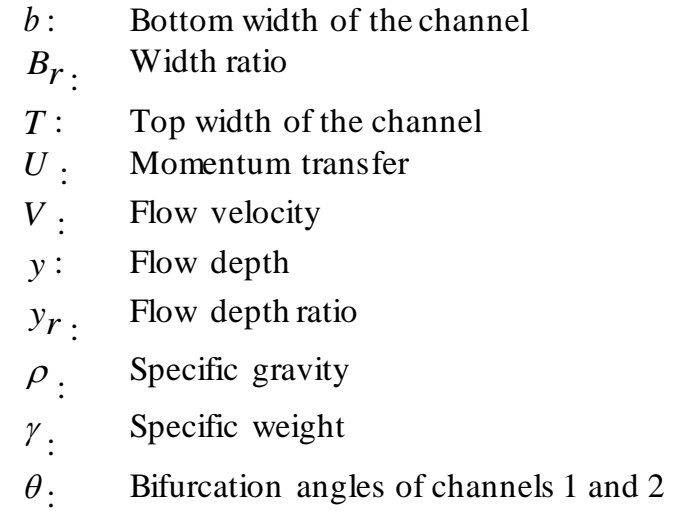

\section{Subscripts}

$0:$ Main channel (Sungai Nenggiri)
$1: \quad$ Channel 1 (Sungai Nenggiri after bifurcation)
2 :Channel 2 (Sungai Anak Nenggiri)
$r$ :Ratio

\section{Acknowledgements}

We would like to take this opportunity to acknowledge and thank the $5^{\text {th }}$ International Conference on the Application of Science and Mathematics (SCIEMATHIC 2019) secretariat for their role in the success of the conference. This research was supported by Universiti Tenaga Nasional (UNITEN) and Universiti Teknologi MARA (UiTM) Negeri Semb ilan, Seremban Campus. The UTM Centre for Industrial and Applied Mathematics (UTM-CIAM), Universiti Teknologi Malaysia provided topic problem for Malaysia Industrial Mathematical Modeling Challenge 2019 (MIMMC2019).

\section{REFERENCES}

[1] S. W. Law. Dividing Flow in Open Channel, Master Thesis, McGill University, Montreal, 1965.

[2] A. S. Ramamurthy, D. M. Tran, L. B. Carballada. Dividing Flow in Open Channels, Journal of Hydraulic Engineering, ASCE, Vol. 116, No. 3, 449-455, 1990.

[3] C. C. Hsu, C. J. Tang, W. J. Lee, M. Y. Shieh. Subcritical $90^{\circ}$ Equal-Width Open-Channel Dividing Flow, Journal of Hydraulic Engineering, Vol. 128, No. 7, 716-720, 2002.

[4] I. M. H. Rashwan. Dynamic Model for Subcritical Dividing Flows in Open Channel Junction, Eight International Water Technology Conference, 511-520, 2004.

[5] N. L. Obasi, J. C. Agunwamba, N. Egbuniwe. Influence of Off-Take Angles on Flow Distribution Pattern at Concave Channel Bifurcation, Nigerian Journal of Technology, Vol. 
27, No. 2, 46-57, 2008.

[6] A. Pandey, R. Mishra. Comparison of Flow Characteristics at Rectangular and Trapezoidal Channel Junctions, Journal of Physics Conference Series, Vol. 364, 1-11, 2012.

[7] G. Kesserwani, J. Vazquez, N. Rivière, Q. Liang, G. Travin, R. Mosé. New Approach for Predicting Flow Bifurcation at Right-Angled Open-Channel Junction, Journal of Hydraulic Engineering, ASCE, 662-668, 2010.

[8] D. A. Tholibon, J. Ariffin. Bifurcation Simulation Modeling Review, International Journal of Sciences: Basic and Applied Research, Vol. 8, No. 1, 45-50, 2013.

[9] A. Zahiri, A. A. Dehghani. Flow Discharge Determination in Straight Compound Channels using Anns, World Academy of Science, Engineering and Technology, Vol. 58, 12-15, 2009.

[10] S. A. Mirbagheri, M. Abaspour, K. H. Zamani. Mathematical Modeling of Water Quality in River Systems. Case Study: Jajrood River in Tehran - Iran, European Water, Vol. 27/28, 31-41, 2009.

[11] Y. Yang, T. A. Endreny, D. J. Nowak. Application of Advection-Diffusion Routing Model to Flood Wave Propagation: A Case Study on Big Piney River, Missouri USA, Journal of Earth Science, Vol. 27, No. 1, 9-14, 2016. 